\title{
Entre presenças e escritos: reverberações da viagem de Marinetti em 1926 na América Latina
}

\author{
Between presences and written: reverberations of \\ the travel of Marinetti in 1926 in the Latin America
}

Rosemary Fritsch Brum*

\begin{abstract}
Resumo: $\mathrm{O}$ texto reflete sobre as viagens de Filippo Tomaso Marinetti à América do Sul, em duas oportunidades, em 1926 e em 1936. Destaca-se a contribuição do futurismo italiano através do seu criador, para um vasto campo da produção artística, literária e até arquitetônica para o continente. Enfrenta-se, ainda que brevemente, a controvérsia sobre a recepção do movimento e o diálogo com as vanguardas latino-americanas. O modernismo e a polêmica recepção brasileira mais a perspectiva platina (Argentina e Uruguai) foram contemplados por comentaristas e pesquisadores que refletem a diversidade de avaliação sobre essas viagens e a recepção artística, intelectual e ideológica do movimento. Por hipótese, partem todos da dimensão histórica, uma vez que quando dessas tournées na Sudamerica, o ímpeto do movimento já havia chegado ao fim em meados da Primeira Guerra Mundial. À medida que o morticínio mecanizado tragava a Europa, tornava-se difícil sustentar o culto à máquina. Ao longo das décadas de 1920 e 1930, a segunda geração de futuristas tentou estender a ideologia e a prática futuristas à instalação, à cenografia teatral, às artes gráficas e à publicidade, alcançando algum sucesso.
\end{abstract}

Palavras-chave: Marinetti. Futurismo. Vanguardas. Modernismo. Performance.

Abstract: The text thinks about the travels of Filippo Tomaso Marinetti to the South America, in two opportunities, in 1926 and in 1936. There stands out the contribution of the Italian futurism through his creator, for a vast field of the artistic, literary production and up to architectural for the continent. It is still faced, that shortly, the controversy on the reception of the movement and the dialog with the vanguards Latin American. The modernism and the controversy Brazilian reception more the Platine perspective (Argentina and Uruguay) were contemplated

* Doutora em História (PUCRS), Mestre em Sociologia (UFRGS), Socióloga do Núcleo de Pesquisa em História do IFCH/UFRGS. Agradecimentos à pesquisa realizada por Katy Rosane Siqueira. 
by commentators and investigators who reflect the diversity of evaluation on these travels and the artistic, intellectual and ideological reception of the movement. For hypothesis, they all leave from the historical dimension, as soon as when of these tours in the Sudamerica, the impulse of the movement had already reached the end in the middle of the First World war. While the mechanized slaughter was swallowing Europe, was becoming difficult the worship supported to the machine. Along the decades of 1920 and 1930, the second generation of futurists tried to spread out the ideology futurists and the practice to the installation, to the theatrical set design, to the graphic arts and to the publicity, reaching some success.

Keywords: Marinetti. Futurism. Vanguards. Modernism. Performance.

Em 2009, completaram-se cem anos do primeiro "Manifesto Futurista" por Filippo Tomaso Marinetti. Comemorações, exposições internacionais, ensaios informaram sobre as reverberações do movimento desde então. As principais exposições na Europa ocorreram no Centro Pompidou, em Paris, na Tate Gallery em Londres, incorporando ainda o futurismo russo e de outros países. Em Milão foi o cenário que apresentou aspectos de todas as manifestações ligadas ao futurismo, tais como teatro, comida, moda, cinema, literatura, pintura, arquitetura, dança, performance, poesia. Buenos Aires talvez tenha sido a única cidade na América Latina a homenagear vigorosamente a data. Abrigou a Colección MART - Museo di Arte Moderna e Contemporânea di Trento e Rovereto, Itália, na Fundación PROA (Mezza, 2009). Essa distinção parece indicar a recepção diferenciada do Futurismo e do pai do movimento entre nós ainda nos dias atuais.

A primeira viagem de Marinetti à América Latina ocorreu em 1926, acompanhado de Benedetta, sua esposa e artista futurista. Compreendia a tournée iniciada pelo Brasil, apresentações nas cidades do Rio de Janeiro, São Paulo e Santos. Na Argentina seriam visitadas as cidades de Buenos Aires, Rosário e Córdoba. No Uruguai apenas a cidade de Montevideo entraria no circuito. Em 1936, retornaria à Argentina (desacompanhado da esposa), para participar do XIV Congresso Internacional do Pen Club, entre os dias 5 e13 de setembro, em Buenos Aires e que redundaria em intenso conflito ideológico e o abandono do evento por parte de Marinetti. O Pen Club é uma associação mundial de escritores e atuante até hoje, cuja proposta é a defesa dos princípios de liberdade de consciência, a negação da guerra. Para Rabossi (2009), por força das controvérsias em torno dos motivos de suas viagens, a imprensa preocupava-se em acentuar como Marinetti era a figura central 
da vanguarda europeia, o que significava evidenciar o peso dessas incursões para o sistema artístico porteño das primeiras décadas do século XX. Indaga: "Por que Filippo Tomaso Marinetti decide vir duas vezes à Argentina?" Para ela "o impacto que estas excursões pela Sudamérica ocasionam nas figuras artísticas e intelectuais locais lhes devolve uma imagem sobre o vigor com a qual Buenos Aires se apresenta por então ante os olhos de um artista como Marinetti”. Segundo ela, "a atenção está deste lado do Río de La Plata". Isto porque "há um promissor, crescente e único estilo vanguardista en la ciudad de las luces. Os grupos artísticos naqueles anos, com sua insistência en armar seratas futuristas, suas declarações a imprensa, a sua intervenção nas polemicas na imprensa, justificam seu esforço em vir nos anos 20 y 30 " (Rabossi, 2009, p. 18-19). A disputa internacional pela presença desta "personagem tutelar da arte europeia" ao colocar Buenos Aires no seu roteiro teria sua justificativa no vigor da arte e da cultura do país. Saítta (1999) ao deter-se sobre essa viagem de 1926 e na repercussão no ambiente argentino, vai prestar mais atenção à cobertura oferecida em particular pelo jornal da noite Critica, de linha sensacionalista e de expressiva tiragem. O jornal percebera que a renovação artística destinada a um público de massa como a avant guarde argentina poderia ser um grande evento jornalístico. Marinetti oferecia uma grande operação de mercado, como de fato foi feito. Conforme ela, embora pelo pouco público presente aos eventos - constituído antes por escritores, intelectuais e membros das elites - a publicação dos artigos por intelectuais e artistas acabaram em transformar Marinetti em evento de mídia.

Para rememorar, o futurismo foi formulado e propagandeando por Filippo Tomaso Marinetti, o "homem cafeína" como ele autodenominou-se. Proclamará: “é da Itália que lançamos ao mundo este manifesto de violência arrebatadora e incendiária com o qual fundamos nosso futurismo, porque queremos libertar esse país de sua fétida gangrena de professores, arqueólogos, cicerones e antiquários (...). ${ }^{1} \mathrm{O}$ poeta, escritor, self-publicist nasceu na Alexandria, Egito, em 22 de dezembro de 1876 e faleceu em 2 de dezembro de 1944. Estudou na Itália, na França e na Suíça. Trajetória versátil que o habilitou a escrever seu primeiro livro bilíngue de poesia, Destruição, em 1904, e já apresentando experiência anárquicas na escrita. Marinetti publicou no jornal parisiense Le Fígaro, em francês, na primeira página, o "Manifesto Futurista", em 20 de fevereiro de 1909. Ali deixava claro que não pretendia que esse fosse

\footnotetext{
Manifesto futurista. Publicado no Le Fígaro em 20 de fevereiro de 1909.
} 
um movimento italiano provinciano, mas que deveria ter uma dimensão internacional. Seu manifesto não apenas desafiava a predominância de Paris como sede dos movimentos de vanguarda, mas também rejeitava qualquer conceito de tradição histórica na arte. Na Itália, o manifesto se difundirá na revista Poesia, em Milão, dirigida por ele, no primeiro número do ano $\mathrm{V}$, março de 1909 . Um mês e meio após da publicação francesa, o manifesto foi publicado em espanhol no jornal argentino La Nación (em tradução de Rubén Dario que se encontrava na capital francesa como correspondente do mesmo). Essa recepção imediata pode levar a crer que as vanguardas argentinas aderiam prontamente ao ideário do futurismo. Mas não foi assim.

Embora sendo basicamente um movimento italiano, tendo vida curta, a teoria e a iconografia futuristas exerceram um impacto duradouro sobre a vanguarda internacional. O "vorticismo", na Inglaterra, e o "raionismo", na Rússia, tiveram uma dívida implícita para com os futuristas italianos. Muitas ideias desenvolvidas pelo grupo O Cavaleiro Azul, pelo dada e pelo construtivismo russo originaram-se dos futuristas. Nos Estados Unidos, Joseph Stella (1877-1946) foi o introdutor das ideias futuristas, como mostrou em seu quadro Batalha de luzes, Coney Island, Mardi Gras (1913-14). ${ }^{2}$ Igualmente a arte da performance e da poesia sonora terá na declamação e nos escritos de Marinetti sua afirmação. Em "A declamação dinâmica e sinótica", de 1916, em Milão, defende que "o corpo do poeta deve desbloquear, tornálo vivo, móvel, contrariando a imobilidade das pernas do declamador 'passadista'(...)". O declamador deve ser "um inventor e um criador incansável, decidindo intuitivamente, a cada instante, o ponto em que o adjetivo-tom e o adjetivo-atmosfera devem ser pronunciados e repetidos (...)" (Minarelli, 1980). É preciso reconhecer, pois, a importância dessa primeira vanguarda europeia italiana para as artes, a literatura, a arquitetura, e em todos os campos abarcados pelo futurismo e sua "máquina de propaganda". Há constantes no discurso público e nas estratégias dos futuristas. Ainda que perca sua força ao longo dos anos compreendidos entre o primeiro manifesto, o de Marinetti (1909) até sua morte (1944), os manifestos se revelaram surpreendentes, autoritários, agressivos, escandalosos, até proféticos. Há tensões, embates com outros projetos estéticos. Como parte das vanguardas históricas, é superado antes que consiga resolver seus conflitos internos. Marinetti perde sua centralidade no movimento que criou. Mas não desiste, em toda sua vida,

\footnotetext{
$2<$ http://www.slideshare.net/turmaweb2010/futurismo-arlane-e-estefani-e->.
} 
da propaganda, da performance. Os futuristas acompanham e louvam o ideal do progresso técnico, científico, a velocidade das máquinas, as transformações na vida moderna. No caso do futurismo italiano atravessou a primeira guerra na Europa, a ascensão das ideologias totalitárias. Seu programa, como acontece com movimentos artísticos que de algum modo contém capacidades expressivas, foi aproximado ao fascismo italiano. Política e arte mesclaram-se. Como diz Mezza, (2009, p. 16) “as palavras serão metrópole, revolução, liberdade, guerra, máquinas, velocidade, ruído, arsenal, locomoção, ritmos, aeroplanos, lutas, destruir, rebelar, exaltar, marchar, e muito mais. Palavras para uma linguagem carregada de questionamentos e ânimos de revisões, de expressões militares e militantes (...)". Tendo sido o primeiro movimento artístico das vanguardas históricas a expressar sua missão dessa forma, (ao todo foram em número de trinta e seis manifestos redigidos entre 1909 a 1931 por vários artistas), quando Marinetti convoca " $A$ todos los hombres vivos de la tierra! essa é uma declaração pública que inaugura uma atitude dos artistas por programas e pela publicação de um manifesto no campo da arte e da cultura.(...) são, como documentos, um ponto de encontro entre instancias teóricas, poéticas, políticas e ideológicas e constituem um gênero híbrido, com força persuasiva e capacidade - formal e técnica - de difundir pensamentos que estão em vias de ação (...) (Marinetti, 1909 apud Mezza, 2009).

Refletir, pois, sobre as viagens de Marinetti à América do Sul exige enfrentar uma controvérsia sobre a recepção do futurismo e o diálogo com as vanguardas latino americanas, mormente a brasileira, Esse percurso foi percorrido, esmiuçado, entre outros, para o Brasil, por Annateresa Fabris (1994) e que é obra de referência. ${ }^{4}$ Na literatura sobre a vertente platina, cito apenas um pequeno elenco representado por autores como Catarulla (1998), Vasquez (2005), Alcalá (2009) e Cecília Rabossi (2009). Afirmam os pesquisadores que quando dessas tournées na Sudamerica, o ímpeto do movimento já havia chegado ao fim em meados da Primeira Guerra Mundial. À medida que o morticínio mecanizado tragava a Europa, tornava-se difícil sustentar o culto à máquina. Ao longo das décadas de 1920 e 1930, a segunda geração de futuristas tentou estender a ideologia e a prática futuristas à instalação,

Ver também o lançamento recente de 100 Artists' Manifests from the Futurists to the stuckists selected by Alex Danchev. London: Pinguin Books (Modern Classics), 2011.

4 Fabris (1994). (Estudos; v. 13). Barros, (2010). Ver SCHNAPP, Jeffrey T., ROCHA, João Cesar de Castro. Brazilian Velocities: on Marinetti's 1926 Trip to South America. South Central Review 13.2-3 (Summer-Fall 1996) p. 105-156. Captado em: 7 set. 2010. 
à cenografia teatral, às artes gráficas e à publicidade, alcançando algum sucesso. Captar a sensação do vôo era algo que chegava até mesmo a ser defendido pelos futuristas, em seu "Manifesto da aeropintura", de 1929, que assinalou o início da fase final do movimento. ${ }^{5}$ Copetti $(2007$, p. 80$)$ comenta que "(...) entre 1909 e 1915 é que fora definida como o período heróico do movimento; a segunda, entre 1916 e 1918, momento em que se unem ao grupo nomes como os de Bruno Corra, Enrico Settimelli e Umberto Sant'Elia, cujos interesses estão focados no teatro, cinema e política; e, por fim, a terceira fase, que engloba os anos entre de 1918 e 1920 e possui um viés sócio-político".

No Brasil, os modernistas brasileiros como Mario de Andrade não acompanham as propostas futuristas, negam-na, em todas as ocasiões. Alguns autores como Motta Junior, chegam a distinguir entre futurismo e marinettismo ${ }^{6}$ (Fabris, 1994, p.95). Essa atitude funde-se nos significados presumíveis sobre os vários caminhos que o modernismo trilhará após a "Semana de 22" segundo Fabris (1994). Para a autora, ao tomar São Paulo "como o epicentro nacional de uma renovação também no campo cultural, nas artes, e interdependência entre modernidade e modernização, figura a recepção de Marinetti no quadro de elaboração do modernismo brasileiro". Tece a hipótese segundo a qual o diálogo/ embate com Marinetti tem seu ponto terminal em Macunaíma (de Mario de Andrade). Após a recusa da civilização industrial, começa a tomar corpo um novo projeto estético, ao qual a década de 30 conferirá contornos políticos e imporá novas diretrizes de atuação artísticas, bem diferentes da agressividade e da polêmica acirrada do futurismo (Fabris, 1994, p. 265-185). Secundando Amaral (1998) concorda com Brito (1997) para quem o movimento futurista foi uma "pecha que continuava sendo dada aos modernistas". E cita Mário de Andrade dizendo que Mário tentou em vão desfazer o equívoco da comparação que muitos críticos, daquela época faziam a eles, os Modernistas, chamando-os de Futuristas. O modernista teria afirmado que "a erronia, é verdade, começou por nós. Oswald de Andrade chamou-nos futuristas um dia. Mas o largo sentido em que tomava a palavra foi bastante explicado mais tarde por ele mesmo e luminosamente em seguida, numa crônica de Hélios, por Menotti Del Picchia. E no Jornal do Comércio, de 6 de junho passado, assinei um artigo em que me excluía do futurismo.

\footnotetext{
$<$ http://www.slideshare.net/turmaweb2010/futurismo-arlane-e-estefani-e-debora2>.

6 Utilizei longamente as descrições dessa obra, basicamente o capítulo Abaixo Marinetti, p. 218-259 e a pesquisa de Barros (2010).
} 
E Buarque de Hollanda parece ter dito qualquer coisa também pelas revistas do Rio". 7

Esse contexto brasileiro acolhe Marinetti em 1926, a bordo do Giulio Cesare, quando aporta a 13 de maio no Rio de Janeiro, cumprindo o roteiro montado pelo empresário italiano Niccolino Viggiani que previu além das conferencias, passeios, encontros com associações de italianos e concessão de entrevistas. Foi recepcionado pelo escritor Graça Aranha - ex-ministro do Brasil em Paris durante a guerra e autor de Cannã e Malazarte - considerado um amigo dos futuristas italianos, além do embaixador Montagna, o capo del fascio Luigi Sciutto e demais jornalistas. Dessa estada Marinetti escreverá suas impressões no seu diário Velocitá brasiliane. Rio, palcoscenico del teatro Oceano, sempre Interessado em associar as belezas naturais da cidade, ao comentário futurista. Como, por exemplo, na chegada, no comentário durante o percurso de automóvel até o Palace Hotel, deixou registrado: Caro Aranha, Rio de Janeiro é um frutto tropicale. Che há um delizioso succo: la velocitá delle sue automobili (Schnapp; Rocha, 2009). Já sobre o passeio à Favela (hoje Morro da Providencia) e citado nas palestras como "paisagem contrastante e acidentalmente futurista", escreveu no diário (rasurando algumas passagens: “(...) Moro de La favela, rifugio di neri antisociali, quartiere, ornata da palma regali e guardano dall'alto l'insolente ricchezza veloce delle avenide" (Chiarelli, 2002). Os espetáculos foram previstos para os dias 15 e 18, no Teatro Líricoum patrimônio da cidade e demolido em 1934 - com capacidade para 1.500 espectadores. Na primeira noite e acompanhado por Graça Aranha, Marinetti homenageará os "ausentes intelectuais", mas, segundo ele, "os campeões da cruzada futurista”, como Mário de Andrade, Oswald de Andrade, Ronald de Carvalho, Prudente de Moraes, Manoel Bandeira, Renato Almeida, Sergio Buarque de Holanda, Henrique Pongetti (Fabris, 1994, p. 222). O que aconteceu nessa conferência tratou-se de um embate de Marinetti com a plateia dividida entre simpatizantes, curiosos e declaradamente hostis à presença do poeta no Brasil. Estudantes, italianos emigrados por motivos políticos, comunidade italiana local e jornalistas, assistem à declamação performática dos poemas $O$ combate na montanha e ao Bombardeio de Andrinopla conforme a dicção futurista e suas onomatopeias, o que terá o efeito de

Amaral, (1998). A autora descreve suas fontes: Mário de Andrade, “A semana futurista”, "Pró" (Notas de Arte) in A Gazeta, 4 de fevereiro de 1022; Depoimento de Sérgio Buarque de Hollanda à Autora a 11 de março de 1970. Ver Brito(1997). Vê também, Teles (2009). 
aumentar o estranhamento do público. Na cobertura jornalística da época, Marinetti teria tentado intercalar descrições e impressões sobre a cidade e suas belezas naturais "a sensibilidade agressiva e luminosa, de luz intensa e de vida alucinante do Brasil", assim como comentários sobre comportamento, moda, a grandeza da Itália e suas relações amistosas com o Brasil. As vaias, apupos foram interpretados pelos jornalistas como ao gosto das provocações inauguradas pelos futuristas do primeiro período, mais a mescla confusa entre ideologias e poéticas, odes à Itália, evocações contra o "passadismo" $e$ o papel demolidor e renovador representado pelo futurismo Essa crescente polarização entre futuristas e antifuturistas, fascistas e antifascistas teria sido incitada pela imprensa local no que Barros (2010) denomina "esquentamento" quando há promoção do espetáculo- seguido de uma certa neutralidade, livre para abordagens variadas, caso desejarem. E o faziam de modo cruel, após cada apresentação (Barros, 2010, p. 5-19). No dia 18 de maio tem lugar um concerto futurista (conferencia, irradiação de músicas, leitura de poemas de Manoel Bandeira) na Rádio Mayrink Veiga; à noite, a conferência programada, ficou célebre Há exacerbação por parte de Marinetti, ao unir futurismo e fascismo "por serem ambos realizadores". Precedido de forte suporte policial, o poeta não conseguiu ultrapassar o tumulto e retirou-se do palco. No dia 19 proferiu uma conferência seguida de leitura de poemas na Rádio Sociedade, tendo sido apresentado por Ronald de Carvalho. Nessa ocasião conseguiu fazer suas declamações e proferir seus conceitos para uma plateia interessada em desfazer a má imagem da noite anterior. Parte então para São Paulo com a conferência prevista para o dia 24, no Cassino Antártica. Novo tumulto, mais agressivo que o verificado no Rio de Janeiro. Impedido de apresentar-se, proferiu a sentença que agastará principalmente a Mário de Andrade: "se os futuristas não estão aqui é porque estão todos no Rio. Aqui está apenas um único futurista, Benedetta, que não está aqui porque é minha esposa [...] mas porque é uma grande e genial pintora futurista" (Fabris, 1994, p. 228). Mario de Andrade posteriormente tentou explicar sua ausência: o fundador do futurismo está apenas repetindo-se desde 1909, a vaia no Cassino Antártica foi encomendada por ele mesmo, há renovação nos debates dentro do modernismo sobre essa influencia futurista, a visão sobre o visitante é que se trata de um "delegado do fascismo". Em vista dessas situações, a conferência do dia 27 exigirá uma declaração de Marinetti, a de que não está em viagem de caráter político, apenas artístico. Ao encerrar a conferência com a declamação de poemas, dentre os quais $O$ bombardeio de Andrinopla, a performance 
foi destacada na imprensa como "ação mágico-oratória". No dia seguinte, o casal parte de trem para Santos. Tentará apresentar-se em 1 de junho no Teatro Parquet Balneário. Em vão, reproduz- se a cena ocorrida em São Paulo. De volta a São Paulo, proferiu sua última conferencia no dia 3 de junho no Cassino Antártica, com o tema "De Michelangelo a Boccioni". Alguns críticos o viram como "passadista". A bordo do vapor Re Vittorio Marinetti e Benedetta partem com destino a Buenos Aires. Antes disso, ocorreram reverberações também no Rio Grande do Sul. Para o escritor Augusto Meyer, o poeta italiano teria vindo "agitar em nosso ambiente verde uma nova harmonia necessária, uma vez que parecíamos obrigados a um servilismo tedioso, com um falso incenso e tabus clássicos" (p. 104). No mesmo artigo intitulado $O$ poeta rubro, ainda que não veja influencia de Marinetti nos futuristas como Folgore, Govoni ou Pallazzeschi; ironicamente concorda quando esse propõe "destruir os museus e fuzilar todos os comendadores é de um enorme, quase monstruoso bom senso". A revista Kosmos publica ainda em março uma paródia do manifesto (com pseudônimo) e em junho lança uma nota desafiando os modernistas realmente "a renegarem o Futurismo como propalavam" " (Leite, 1972). Algumas hipóteses para esse repúdio podem estar na recepção e na orientação do modernismo no país. Durante essa viagem e a partir de então, modernistas negam sistematicamente a adesão ao futurismo. É preciso remeter novamente ao movimento modernista com a Semana da Arte Moderna em São Paulo, a pretexto de comemorar o centenário da Independência do Brasil. Para o crítico de estética e filosofia Nunes (1998), "a liberdade de expressão por meio do verso livre, a recusa do parnasianismo, a representação realista na prosa e nas artes, oferecem os contornos do modernismo no Brasil que surgiu da convergência entre a modernização econômico-social e a reprovação do pensamento filosófico, estético e político". Para o crítico Chiarelli (2002) a intenção de criar uma arte nacional terá impedido os modernistas de avançarem na adoção "das formulações mais avançadas e desestabilizadoras da arte, levantadas por alguns segmentos das vanguardas históricas europeias". (...) Serão levados a aproximarem-se antes das tendências do Retorno à ordem internacional - surgidas entre as duas guerras mundiais - do que as vanguardas mais radicais, a necessidade ao realismo (mesmo que sintético) e a valorização do nacional (p. 28). Cabe explicar: o fenômeno artístico conhecido como Retorno à ordem europeia e norte-americana

Ver Jahn (2005). 
predomina no período entre - guerras. É a produção artística que não segue mais o caminho das vanguardas. No Brasil, pois, exercerá grande influencia o Novecento italiano. Conforme a crítica de arte italiana Bossaglia (Chiarelli, 2002, p. 60-85), busca-se depurar da vulgata, que via o Futurismo italiano como movimento artístico fascista italiano. Exatamente por opor-se às vanguardas históricas, experimentais e internacionalistas, combatendo a tradição, o retorno à ordem proposto pelo Novecento foi de certo modo e por determinadas circunstâncias conotado como braço estético-artístico do fascismo. Ao final dos anos 20 coloca-se como a grande arte nacional da Itália fascista, ainda que receba críticas internas. Conclui Chiareli (2002) que no Brasil, "com exceção de Anita Mafalti até 1916, toda produção deve ser lida a partir do Retorno à ordem internacional. (...) Afinal, em 1922, ano da Semana da Arte Moderna, arte internacional já se encontra em pleno universo do retorno à ordem, universo este que irá influenciar todos os artistas ligados ao Primeiro Modernismo" (Chiarelli, 2002, p. 72).

\section{Marinetti em Buenos Aires e em Montevideo}

De toda maneira havia um ímpeto renovador: as vanguardas rioplatenses, para Alcalá (2009), estavam compostas por jovens interessados em romper com o modernismo de Darío, corrente com origem na Hispanoamérica. ${ }^{9}$ Marinetti declara ao aportar em 6 de junho: "Na minha chegada a Buenos Aires, alguns diários me apresentaram sob o aspecto de um homem político mascarado de poeta futurista, vindo a América para ensinar o fascismo [?]. Sou em maior ou menor medida, como os futuristas, a partir de Giotto, de Michelangelo, a Manet, Fattori, Previati, fascista sem carnet, orgulhoso de haver colaborado na grandeza da Itália de hoje (...)." ${ }^{10}$ As apresentações e os temas foram: dia 11 de junho, Teatro Coliseu: "Origens e verdadeiro conceito de futurismo"; dia 12 de junho, Aula Magna da Faculdade de Ciências Exatas, Físicas e Naturais da Universidade de Buenos Aires: "Futurismo na arquitetura";

9 Alcalá, (2009). O retorno da Europa de Jorge Luis Borges, em 1921, entre outros, teve dom de aglutinar as expectativas dessa geração. Os canais de difusão serão as revistas Prisma, Proa, Martin Fierro, Nosotros, Inicial, na Argentina. Teseo e Cruz del Sur, em Montevidéu, além de instituições como Amigos del arte. Ver SCHNAPP, Jeffrey T., ROCHA, João Cesar de Castro. op. cit. e SAÍTTA, Sylvia, op. cit. para a cobertura desse roteiro na Argentina e no Uruguai.

10 TORCHIA, Franco. El diário fundado por Mitre fue el principal médio difusor de las propruestas artísticas, las visitas al pais y las polemicas generadas por el impulsionador del futurismo. La Nación, Buenos Aires, Sábado, 10 de abril 2010. Captado em: 4 ago. 2011. 
dia 15 de junho, Teatro Coliseo: "O teatro e o futurismo". Nessa noite, a Revista Martín Fierro oferece um jantar em homenagem ao poeta, onde intervêm representantes das revistas Inicial, Revista de América, Valorações e Estudiantina e contou, entre os convidados, Jorge Luis Borges, Guillermo Korn, Córdova Iturburu, Emilio Pettoruti, Alfredo Bigatti y Xul Solar.

Seguiram-se na programação em Buenos Aires: dia 17 de junho, Associacíon Wagneriana: "Música e músicos de Wagner para Russolo"; no mesmo dia, Associacíon amigos del arte, aula inaugural na exposição de pinturas de Pettoruti, Xul Solar e Noran Borges e dos projetos arquitetônicos de Vautier Prebisch, decorado por Pedro Illari. Em La Plata, Teatro Argentino, dia 19 de junho. Em Córdoba, dia 22 de junho, Faculdade de Engenharia da Universidade de Córdoba. Em Rosário, dia 25 de junho, Biblioteca da Argentina: "Futurismo integral". De volta a Buenos Aires, Teatro Coliseo, dia 27 de junho: "Os esportes, jogos de azar, luxo, moda, cabelo longo e 'tactilismo' (arte nova)”. Em Montevideo sua apresentação no Teatro Artigas, em 29 de junho, encerrou a jornada. Em todo o percurso Saítta (1999) percebe um esvaziamento gradativo da cobertura jornalística. Apenas a revista Martin Fierro positiva a excursão, no editorial "Martín Fierro e Marinetti". Ressalta como "as suas palestras eram entregues "às massas", e pelo reconhecimento que mais que o artista de vanguarda, Marinetti é o propagandista da nova arte. Enquanto que os jornais La Prensa e La Fronda são acusados por faltarem em discutir as teorias futuristas. ${ }^{11}$

Fim da intensa jornada de 1926, Marinetti e Benedetta embarcam rumo à Europa.

\section{Referências}

100 Artists' Manifests from the Futurists to the stuckists selected by Alex Danchev. London: Pinguin Books, 2011. (Modern Classics).

ALCALÁ, May Lorenzo. La esquiva huella del Futurismo em ela Rio de La Plata. La Argentina futurista: Marinetti en Buenos Aires. Publicado no Catálogo da Exposição El universo futurista: 1909-1936. Colección MART - Museo di Arte Moderna e Contemporânea di Trento e Rovereto, Itália. Curadora: Gabriella Belli. Buenos Aires: Fundación PROA, 2009. p. 18-19.

AMARAL, Aracy A. 1930 - Artes plásticas na Semana de 22. São Paulo: Ed. 34, 1998. A autora descreve suas fontes: Mário de Andrade, "A semana futurista", "Pró" (Notas de Arte). In: BARROS. Martín Fierro, Buenos Aires, segunda época, año III, n. 30-31, p. 5-19, 8 jul. 1926.

${ }^{11}$ REVISTA Martin Fierro. Buenos Aires, segunda época, ano III, n. 30-31. p. 5-19 
BARROS, Orlando de. O pai do Futurismo no país do futuro. As viagens de Marinetti ao Brasil em 1926 e 1936. Rio de Janeiro: E-Papers, 2010.

BRITO, Mário Da Silva. História do modernismo brasileiro. Antecedentes da semana de Arte moderna. Rio de Janeiro: Civilização Brasileira, 1997.

CATTARULLA, Camila. Adán Buenosayres: periferie urbane e identitá nazionale, in Città reali e immaginarie del continente americano. A cura di Cristina Giorcelli, Camila Catarulla e Anna Scacchi. Roma: Edizione Associate, n. 1, São Paulo, june 2005 nov, 1998.

CHIARELLI, Tadeu. Arte internacional brasileira. São Paulo: Lemos, 2002.

COPETTI, Rafael Zamperetti. Futurismo italiano e modernismo brasileiro. Florianópolis: UNILETRAS 29, dez. 2007.

FABRIS, Annateresa. O Futurismo paulista. Hipóteses para o estudo da chegada da vanguarda ao Brasil. São Paulo: Perspectiva/EDUSP, 1994. (Estudos, v. 13).

JAHN, Dilamar P. A nação brasileira entre o fato e a Ficção. Literatura e questão nacional na imprensa portoalegrense entre 1922 e 1937. Dissertação (Mestrado) Programa de Pós-Graduação em Literatura, UFRGS, Porto Alegre, 2005.

LEITE, Ligia Chiapinni Moraes. Modernismo no Rio Grande do Sul. Materiais para estudo. São Paulo: Instituto de Estudos Brasileiros, 1972.

MANIFESTO futurista. Publicado no Le Fígaro em 20 de fevereiro de 1909.

MARINETTI, F.T. A todos los hombres vivos de la tierra! Fundación y manifiesto del Futurismo, 1909 apud MEZZA. El poder de la voz escrita. Catálogo da Exposição El universo futurista: 1909-1936. Colección MART - Museo di Arte Moderna e Contemporânea di Trento e Rovereto, Itália. Curadora: Gabriella Belli. Buenos Aires: Fundación PROA, 2009.

MEZZA, Cintia. El poder de la voz escrita. Catálogo da Exposição El universo futurista: 1909-1936. Colección MART - Museo di Arte Moderna e Contemporânea di Trento e Rovereto, Itália. Curadora: Gabriella Belli. Buenos Aires: Fundación PROA, 2009.

MINARELLI, Enzo. A voz. Instrumento de criação. In AAvv. IL colpo di glottide. Firenze, Vallecchi, 1980.

NUNES, Benedito. Crivo de papel. São Paulo: Ática, 1998.

RABOSSI, Cecília La Argentina futurista: Marinetti en Buenos Aires. Catálogo da Exposição El universo futurista: 1909-1936. Colección MART - Museo di Arte Moderna e Contemporânea di Trento e Rovereto, Itália. Curadora: Gabriella Belli. Buenos Aires: Fundación PROA, 2009.

SAÍTTA, Sylvia. Futurism, fascism and mass-media: the case of marinett"s trip to Buenos Aires. Stanford Humanities Review. Vol 7.1,1999.

SCHNAPP, Jeffrey T.; ROCHA, João Cesar de Castro. Brazilian Velocities: on Marinetti's 1926 Trip to South America. South Central Review 13.2-3 (Summer-Fall 1996), p. 105-156.

TELES, Gilberto Mendonça. Vanguarda europeia \& modernismo brasileiro. Petrópolis: Vozes, 2009.

TORCHIA, Franco. El diário fundado por Mitre fue el principal médio difusor de las propruestas artísticas, las visitas al pais y las polemicas generadas por el impulsionador del futurismo. La Nación, Buenos Aires, Sábado, 10 de abril 2010. 
VASQUEZ, Karina R. Vasquez Redes intelectuais hispano-americanas na Argentina de 1920. In: Tempo Social, São Paulo, v. 17, n. 1, June 2005.

\section{Fontes:}

DEPOIMENTO de Sérgio Buarque de Hollanda à Autora em 11 de março de 1970.

JORNAL A Gazeta, 4 fev. 1022.

\section{Sites:}

$<$ http://www.slideshare.net/turmaweb2010/futurismo-arlane-e-estefani-e->. Acesso em: 07 jul. 2011.

$<$ http://www.slideshare.net/turmaweb2010/futurismo-arlane-e-estefani-e-debora2>. Acesso em: 07 jul. 2011. 